\title{
An Application of Active Learning and Distance Education
}

\author{
Thomas Pencek \\ Meredith College, USA
}

pencekt@meredith.edu

\author{
Dennis Bialaszewski \\ Indiana State University, USA
}

sdiessie@mama.indstate.edu

\begin{abstract}
This paper discusses the planning and observations of a group project using the Internet between two schools, one in Indiana and one in North Carolina. Students at each school are members of a group assigned to do some financial research on the Internet. Specifically, two companies are researched by each group and two financial ratios computed and compared. Finance students in North Carolina have the assignment to explain the meaning of the two ratios to their colleagues in Indiana, who are mainly freshmen Management Information Systems students. The goals are to promote the use of the Internet, active learning, and teamwork. Despite some problems, the project is deemed to be a success.
\end{abstract}

Keywords: Teamwork, Active Learning, Financial Ratios

\section{Introduction}

The Internet is increasingly being integrated into the curriculum of Schools of Business. It is also possible to use search engines such as Yahoo, Excite, etc., to search for information on a myriad of topics. Furthermore, many companies have structured their home pages to provide information concerning information such as products for sale, job opportunities, and some include their annual reports. Moreover, Corporate Advisory Boards to Schools of Business provide feedback about the need for teamwork skills for their employees and the need for their employees to be literate in e-mail procedures. Therefore, teamwork has become a part of the pedagogy for these Schools of Business. Cyber teams are a possibility with the use of the Internet in which experiential learning can also be applied. It is imperative that we offer our students the best possible education utilizing the technologies available.

Material published as part of this proceedings, either on-line or in print, is copyrighted by the author with permission granted to the publisher of Informing Science for this printing. Permission to make digital or paper copy of part or all of these works for personal or classroom use is granted without fee provided that the copies are not made or distributed for profit or commercial advantage AND that copies 1) bear this notice in full and 2) give the full citation on the first page. It is permissible to abstract these works so long as credit is given. To copy in all other cases or to republish or to post on a server or to redistribute to lists requires specific permission from the author.
This paper discusses a group project involving two schools, Indiana State University and Meredith College. The class at Indiana State University is the Introduction to Management Information Systems (MIS) and the class at Meredith College is Intermediate Corporation Finance. Students from each school are assigned to teams to get to know one another and research certain publicly traded corporations whose main business involves computers and accessories. They are expected to obtain financial information and calculate two financial ratios. The main data source used is the web sites of companies who maintain them. Students are encouraged to seek out other pertinent sites such as EDGAR and EDGAR-ONLINE which provides certain financial information. The project took place during the spring 2000 semester.

\section{Project}

Students at each school are assigned to different groups. The overall project has the students of each group collecting financial information concerning two companies who are in the computer business. The information of the two companies are compared and discussed. The project consisted of three phases.

Phase one involves a getting to know one another in the group. They are expected to communicate certain personal information such as hometown, major, etc. Students had to combine this information for all team members and then send it as an attachment to the respective professors for 
grading. A hard copy of their paper was not accepted. For the class in Indiana, the students had to present the information on their groups to their classmates.

Phase two has the students communicate their computer backgrounds to one another. In this phase, the computer courses taken are exchanged between the two schools. Furthermore, they report on the computer facilities available at their respective schools. Examples of such information are the number of labs, type of computers, etc. Another part of this phase was the research on the background of the companies that each team analyzes. Examples of such information expected included the main business of the companies and any subsidiaries. This information is compiled and sent as an attachment to each professor and grading. As with phase one, students in Indiana are required to present the information obtained

Phase three is the primary purpose of the endeavor. From the EDGAR database or company's web site; students are required to compute two common financial ratios. These ratios are the net profit margin and total asset turnover. In Finance pedagogy, these two ratios determine the return on assets ratio. The students are required to compute these ratios for two companies that are in the computer industry. Companies who compete with one another are selected for analysis. The reason for such a decision was to compare the two firms. An example of this might be Microsoft and Apple. Students in the Corporate Finance class are expected to explain what these ratios are measuring and compare the two companies. Students in the MIS class are expected to present the results and what they learned from their colleagues at Meredith College. The students in Indiana present their knowledge to the class. The grade at both Indiana State and Meredith College is based on the presentation. Furthermore, the students are expected to turn in a hard copy of all three phases via an attachment. Finally, the students were expected evaluate one another within their groups as to effort.

Ten students were originally registered in the class at Meredith College and 17 at Indiana State University. Therefore, five teams are formed for the project, two students from Meredith College and three to four from Indiana State University. Each team was assigned two computer industry stocks and the companies are to be publicly traded. The companies chosen are ones that may not be the most recognizable names in the computer industry. This was by design so that the students are made aware of various companies that are in the computer industry. Wherever possible, teams are assigned companies who compete with one another. The names of the companies used for the project are Adobe, AMD, Cisco Systems, Compuware, Nortel
Networks, Oracle, Polycom, Red Hat, Texas Instruments and $3 \mathrm{Com}$.

\section{Goals and Objectives}

One of the main goals of the projects is to show how teamwork can be enhanced through the use of the Internet. More companies are having their employees work in teams and use the Internet. It is more interesting that the students from each school did not meet face-to-face. Therefore, the use of e-mail is critical. Furthermore, it is an application of active learning for the Finance students since it was their responsibility to "teach" the MIS students some financial concepts. The students learned first hand how the Internet enhances their knowledge and research skills. The use of real-life companies with complex financial statements is another learning experience. The complex financial statements are an area of particular importance. Most finance textbooks use very simple financial statements.

The integration of the two functional areas is an important consideration. From the MIS standpoint, the students learn about the availability and use of databases and the Internet. In addition, the use of e-mail and attachments is an important skill for students to have.

\section{Challenges and Considerations}

Planning the project presents some challenges. As mentioned earlier, attachments were required so that there would be no compatibility problems. Some computers at Indiana State can only work with ASCII attachments. First, most of the students in the MIS class are freshmen. The students in the Finance class are mostly seniors. The computer skills of the MIS students are expected to be minimal. The students in the Finance class are expected to have a higher level of computer literacy, which was not found to be the case.

Another problem was timing of assignments. The first month of classes was not used since the faculty member at Indiana State had to teach certain e-mail techniques at this time. Classes started about one week apart. Spring breaks of the schools presented another problem since they did not coincide. Therefore, two weeks of the semester were lost due to spring breaks. Given this, it was decided that phase one was due by the middle of February and phase three was due at the end of February. Early April was agreed upon as the due date for phase three.

Another issue dealt with the grading of the project. For the students to take the project seriously, the professors agreed to have the project as a whole count at least 20 percent of 


\section{An Application of Active Learning and Distance Education}

the student's final grade. Due to past experience, it was felt a lower figure would not provide enough incentive for the students to perform adequately. This was a problem previously where one school had a low weight assigned to the final grade; the students did not put much effort into the project.

It was known from a previous project such as this that there could be some transmission delays between the schools. During the course of the project, it was discovered the speed of transmission of e-mails to and from Meredith College was delayed at times. For some reason beyond the control of the students and the professors, the messages could be delayed up to 24 hours. Students were encouraged to get their respective information to their group at least one week in advance of the due date. Deadlines of at least one week in advance were encouraged. In spite of warnings from the professors, it really created some problems for groups that were not ahead of schedule in terms of deadlines.

Firings were allowed of group members. A "firing" is where a member of the group was dismissed for nonperformance. When a student is "fired", they fail the project and their overall grade for the course is less. Given that the project is worth twenty percent of their grade, it was felt that this would be an inducement for the student to contribute to the group.

\section{Observations}

One of the first observations was that some students did not take the project seriously. An explanation of why this is so is not available. The faculty members involved assumed that by making the project 20 percent of their grade would make them care. Examples of a non-caring attitude were ignoring information from other team members, tardiness in the sharing of information required for the project, incomplete projects, and some "firings." Other problems that occurred included lack of attendance in class at Indiana State, extraneous information sent to faculty, one student did not want to be part of any groups, and the specific instructions relating to files was ignored.

Another problem that developed with certain groups was the dropping of class. One student Meredith College and two students at Indiana State did not finish the course. This created some problems for their groups. The most obvious problem was that one group only had one member from Meredith College. Furthermore, two firings took place during the course of the project.
Some problems occurred on the Meredith College end. First, it was discovered that some students did not know how to do an attachment. Others did not know how to set up a mailing list. As was the case with the Indiana State students, a couple did not take the project serious.

On a positive note, successful teams noticed they had a strong facilitator. Some students took the responsibility to get the project done on time. Another issue is the timing issue where students waited until the last day to actually complete the requirements of the project.

In spite of the problems encountered during the project, the professors deemed the project a success for the following reasons. First, the presentations were judged to be of high quality. They explained the ratios very well. Second, students at both schools developed a greater appreciation of the use of the Internet. In interviewing students at the end of the semester, students found the project to be useful and enjoyable. Furthermore, their electronic mail skills are enhanced; they developed a greater understanding of people who live in a different section of the country; and developed a greater appreciation for teamwork and its implications. Finally, they developed a working knowledge of complex financial statements.

At the beginning of the project, the professor of the Finance course recommended that the students use the companies' web sites for their research. However, the professor found those web sites such as Yahoo and fool.com to be user friendly and provides some important information and will recommend them to future students.

\section{Conclusions}

In spite of the above problems, most student feedback on this project was positive. They learned to work with others of diverse backgrounds in order to complete a common goal. There are many potential courses where students may be teamed together and sharpen their knowledge in a course integrating the material in a real world situation with another course. Moreover, students develop an understanding of global electronic teams in exploring issues. For example, this pedagogy has been utilized teaming students from a Midwest university with one from South Africa. A derivative result of this pedagogy is that it becomes a real habit for students to rely on e-mail and the internet for communication as they learn with hands on how much can be accomplished working with others who are not in close proximity. Another result is that they learn that others across the country are not as different as they first might think and some teammates at the other university might be better teammates than those who are at the same university. 
Furthermore, since they had to depend on each other, they were not known to one another, there was an implicit peer pressure as others were counting on them to produce and they did not want to look bad in the eyes of their "remote" teammates. It may also be due to a school pride situation where they did not want to make their school look bad by not performing. Finally, MIS and Finance material was fortified by this hands-on experience.

Most of the goals were achieved. Most are addressed above. Furthermore, the Internet was found to be a resource and led to increased productivity. Finance students developed a better understanding of complex financial statements.

\section{References}

1. Amman, H., Kendrick, D., “Active Learning,” Journal of Economic Dynamics and Control, Jan. 1994

2. Bialaszewski, D., Pencek, T., Zaher, T., "Intergrating the Internet into Finance Courses," Proceedings of Academy of Financial Services, 1995.
3. Bialaszewski, D., Case, T., Pencek, T., Oberholzer, M., and Wood, R., "Pitfalls to Avoid When Incorporating Electronic Teams Into Coursework," Proceedings of International Academy of Information Management, 1997.

4. Smith, P., Peters, V., “Action Learning: Worth a Closer Look," Ivey Business Quarterly, Fall 1997, Vol. 62, Issue \#1.

\section{Biographies}

Thomas Pencek is Associate Professor at Meredith College where he teaches Finance. Prof. Pencek has authored numerous papers dealing with teamwork and distance education.

Dennis Bialaszewski is Professor of MIS at Indiana State University. Dr. Bialaszewski has written various articles dealing with distance education and has serve as a panelist several times dealing with issues related to distance education. 